\title{
Emotional memory persists longer than event memory
}

\author{
Kenichi Kuriyama, ${ }^{1}$ Takahiro Soshi, Takeshi Fujii, and Yoshiharu Kim \\ Department of Adult Mental Health, National Institute of Mental Health, National Center of Neurology and Psychiatry, Kodaira, \\ Tokyo 187-8502, Japan
}

\begin{abstract}
The interaction between amygdala-driven and hippocampus-driven activities is expected to explain why emotion enhances episodic memory recognition. However, overwhelming behavioral evidence regarding the emotion-induced enhancement of immediate and delayed episodic memory recognition has not been obtained in humans. We found that the recognition performance for event memory differs from that for emotional memory. Although event recognition deteriorated equally for episodes that were or were not emotionally salient, emotional recognition remained high for only stimuli related to emotional episodes. Recognition performance pertaining to delayed emotional memory is an accurate predictor of the context of past episodes.
\end{abstract}

[Supplemental material is available online at http://www.learnmem.org.]

Memories of events evoking strong emotions, especially fear, selectively persist (Bradley et al. 1992; Breslau 2001; Coles and Heimberg 2002; Wagner et al. 2006) because emotion enhances event-memory retention. The hippocampus is crucial in processing declarative and spatial long-term memory, whereas the amygdala drives emotion processing and emotional memory formation (LaBar and Cabeza 2006; Suzuki 2009). Whether or not emotion enhances event memory retention is controversial. By using photographs with affective valence as both encoding and recall stimuli, some authors found that emotion accelerates episodic memory encoding (Bradley et al. 1992; Maratos et al. 2001; Smith et al. 2004, 2005; Wagner et al. 2006). However, others speculate that emotion simply heightens the subjective sense of remembering, and that increase in the subjective ratings of vividness, recollection, and belief in accuracy does not indicate accurate memory (Talarico and Rubin 2003; Sharot et al. 2004). Experiments involving commonly used photographs as encoding and recall stimuli permit good control of confounding factors (Maratos et al. 2001) and enable rigid event-emotion coupling, but do not allow the examination of the effects of emotion alone on memory encoding. This is because the acute effects of emotion on memory recognition mask the delayed effects of emotion on memory encoding and may be expressed during memory recognition via the memory consolidation process.

Emotional memory may have an independent neural background; the encoding, recognition, and consolidation processes involved in emotional memory may differ from those involved in episodic memory (Cahill et al. 1995; Squire and Alvarez 1995; Adolphs et al. 1997). Amnesic patients with unilateral hippocampal damage can achieve complex emotion-based learning, despite their inability to encode and recall episodic memory (LaBar and LeDoux 1996; Turnbull and Evans 2006). However, amnesic patients with severe bilateral hippocampal damage are incapable of emotion-based learning and episodic memory (Gupta et al. 2009). Different types of memory processes may operate in the formation of emotional episodic memory (Zola-Morgan and Squire 1990; Squire 1992); separate neural systems store memories of emotions and events.

\footnotetext{
${ }^{1}$ Corresponding author.

E-mail kenichik@ncnp.go.jp; fax 81-42-346-1986.

Article is online at http://www.learnmem.org/cgi/doi/10.1101//m.1651910.
}

We hypothesized that intraindividual differences exist in episodic and emotional memory recognition in healthy humans and are associated with delayed not immediate memory, because rigid event-emotion coupling is preserved in immediate memory but weakened by separate memory consolidation processes in delayed memory. To validate these hypotheses, we explored the behavioral features associated with emotional and event memory recall (immediate and delayed) for the same episode by using a novel memory encoding and recognition paradigm, which excludes the overt effects of emotion on episodic memory recognition.

We enrolled 24 healthy participants ( 11 women; mean age, $23.3 \mathrm{y}$; range, 20-33 y) who had no history of drug or alcohol abuse or of neurological, psychiatric, or sleep disorders, and were maintaining a constant sleep schedule. The participants had never been involved in a motor vehicle accident (MVA). They were instructed to refrain from drug, alcohol, and caffeine consumption from $24 \mathrm{~h}$ before the study to the end of the study, and to maintain a normal sleep-wake rhythm verified using sleep logs and an ambulatory wrist activity monitor. All procedures were conducted in accordance with the guidelines outlined in the Declaration of Helsinki. The study protocol was approved by the Intramural Research Board of the National Center of Neurology and Psychiatry; all participants provided written informed consent.

The encoding task entailed watching seven movies each on safe driving (SAFE) and motor vehicle accidents (MVAs), accompanied by real sounds. Each movie was $10 \mathrm{sec}$ long; the interstimulus interval (ISI) was $30 \mathrm{sec}$. All movies showed a typical city street from the driver's viewpoint, recorded via a built-in dashboard camera in a city cab. The MVA movies showed a sudden crash with a speeding oncoming/crossing car/ bike, which appeared without warning in the second half of the movie. No remarkable event occurred in the SAFE movies. All movies were presented in a randomized order counterbalanced across participants, on a 20 -inch $(50.8-\mathrm{cm})$ LCD computer screen; corresponding sounds were presented via headphones. A cognitive (auditory go/no go) task was performed during the ISIs to separate consecutive stimuli.

Two diverse recognition procedures were used: an event-recognition possibly hippocampus-driven procedure and an emotion-recognition possibly amygdala-driven procedure to 
estimate the event- and emotion-oriented output of episodic memory recognition, respectively (Maratos et al. 2001; Smith et al. 2005). The time course of recognition performance was measured $30 \mathrm{~min}$ (day 1) and $9 \mathrm{~d}$ (day 10) after the encoding session by using scenic picture recognition. Both recognition sessions involved the same series of 28 color picture stimuli in a randomized order counterbalanced across participants. The participants were shown 14 pictures each from previously presented movies (OLD pictures) and never-before-seen movies (NEW pictures) recorded via a built-in dashboard camera in a city cab. All pictures were taken from the first $5 \mathrm{sec}$ of the movie to exclude potentially recognizable scenes including accidents. Both types of stimuli were matched in terms of overall visual complexity, brightness, and contrast and contained few recall cues of the other vehicle involved in the accident. The OLD stimuli consisted of seven pictures each from MVA movies (MVA pictures) and SAFE movies (SAFE pictures). The recognition session consisted of 28 14-sec-long trials, in which a fixation crosshair was presented $(7 \mathrm{sec})$ and then the target picture $(7 \mathrm{sec})$. While viewing the stimuli, participants responded to questions on event or emotion recognition.

During event recognition, participants indicated whether they had seen a picture before in the movies shown during the encoding session (OLD) or whether they had never seen the picture before (NEW) by pressing a corresponding key. Once event recognition was established, participants were asked questions to determine emotion recognition. Using a visual analogue scale (VAS), participants rated the degree of fear evoked by the pictures. The VAS was a 100-mm-long horizontal line labeled "No fear" on the left and "Very fearful" on the right. Participants drew a vertical mark on the line at a point corresponding to their degree of fear. VAS scores were determined by measuring the distance of the mark from the left end. Higher scores indicated greater fear. Participants were given no feedback about their accuracy during the session. During the baseline session conducted just before the encoding session by using pictures presented in the recognition sessions, participants simply provided fear ratings.

Four outcomes were possible (Macmillan and Creelman 1991): (1) correct recognition of OLD stimuli (hits); (2) incorrect recognition of OLD stimuli (misses); (3) correct recognition of NEW stimuli (correct rejections); and (4) incorrect recognition of NEW stimuli (false alarms). Trials with no response or in which participants pressed both buttons were considered misses or false alarms. Recognition performance was calculated using response accuracy ([hits/(hits + misses)] or [correct rejections/(correct rejections + false alarms)]). For each recognition session, we calculated the change in fear ratings (relative to the baseline) (change in fear ratings $\left.=\mathrm{VAS}_{\text {(recognition) }}-\mathrm{VAS}_{\text {(baseline) }}\right)$. For detailed information on memory-assessment procedures, see Supplemental Figure 1.

During all sessions, skin conductance response (SCR; in microsiemens $[\mu \mathrm{S}]$, a unit of electrical conductance) (Schell et al. 1991) was also measured to estimate the impact of the stimuli (movies and pictures) on immediate and delayed physiological reactions. We also calculated the change in SCRs (relative to the baseline) (change in SCRs $=$ $\mathrm{SCR}_{\text {(recognition) }}-\mathrm{SCR}_{\text {(baseline) }}$ ) for each recognition session.

In the encoding session, MVA movies had potentially greater psychophysiological impact than SAFE movies; in the recognition sessions, contextual fear conditioning was not associated with context (Dimberg 1987). SCRs pictures.
A

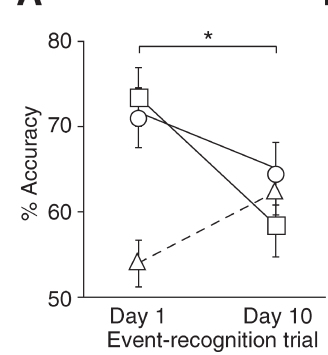

B

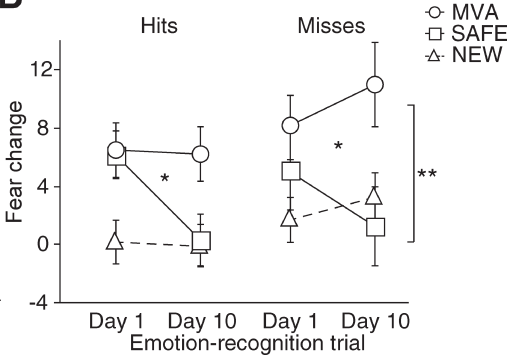

Figure 1. Time courses of recognition performance in relation to recognition accuracy $(A)$ and the change in fear ratings $(B)$. The points and error bars represent the mean and SEM values, respectively. (A) A significant difference in recognition accuracy was observed between days 1 and 10 but not between MVA stimuli and SAFE stimuli. On day 10, the recognition accuracy for both MVA and SAFE stimuli nearly equaled that for the NEW stimuli. $(B)$ The change in the fear ratings, regardless of whether the stimuli were accurately remembered, significantly differed between the MVA and SAFE stimuli but not between days 1 and 10 . Interaction between context (MVA and SAFE) and day was also observed. Second-level analysis revealed that the change in the fear ratings for the SAFE stimuli significantly decreased from day 1 to day 10 , and that on day 10, this change was similar to that for the NEW stimuli, even though the change for the MVA stimuli remained high. ${ }^{*} P<0.05$, $* * P<0.005$.

were significantly higher during MVA movies $(0.110 \pm 0.025 \mu \mathrm{S})$ than during SAFE movies $(0.057 \pm 0.013 \mu S)\left(t_{(167)}=8.12 ; P<\right.$ 0.0001 , paired $t$-test). In the baseline session, the mean SCR did not differ between MVA and SAFE pictures $(0.020 \pm 0.0003 \mu \mathrm{S}$ for both) and between OLD $(0.020 \pm 0.0003 \mu \mathrm{S})$ and NEW $(0.021 \pm 0.0007 \mu \mathrm{S})$ pictures $(P=0.350)$.

The picture stimuli categorized into three contexts (MVA, SAFE, and NEW) were balanced and did not evoke distinct emotional responses. In the baseline session, fear ratings did not significantly differ (paired $t$-tests) between OLD and NEW stimuli ( $P=0.554 ; 40.0 \pm 1.31$ vs. $40.8 \pm 1.51$, respectively) or between MVA and SAFE movies $(P=0.614 ; 39.6 \pm 1.35$ vs. $40.4 \pm 1.27$, respectively). The baseline fear ratings of all participants were at intermediate levels for all stimuli in all contexts, indicating that the landscapes shown possibly contained potential alerting factors, although no evidence of an accident was shown.

With regard to within-participant factors, we assessed differences in recognition accuracy by using 2 (context) $\times 2$ (day) analysis of variance (ANOVA), and differences in the change in fear ratings or SCRs by using 2 (context) $\times 2$ (day) $\times 2$ (correctness) ANOVA (changes in correct [hits] and incorrect [misses] responses were separately analyzed; Table 1).

Table 1. Performance in event-recognition (accuracy [percent]) and emotion-recognition trials (change in fear ratings) calculated separately for correct (hits) and incorrect (misses) responses on days 1 and 10

\begin{tabular}{|c|c|c|c|c|c|c|c|c|c|}
\hline \multirow{3}{*}{$\begin{array}{l}\text { Recognition } \\
\text { performance }\end{array}$} & \multirow{2}{*}{\multicolumn{3}{|c|}{ Accuracy (percent) }} & \multicolumn{6}{|c|}{ Change in fear ratings } \\
\hline & & & & \multicolumn{3}{|c|}{ Hits } & \multicolumn{3}{|c|}{ Misses } \\
\hline & MVA & SAFE & NEW & MVA & SAFE & NEW & MVA & SAFE & NEW \\
\hline \multicolumn{10}{|l|}{ Day 1} \\
\hline Mean & 70.8 & 73.2 & 53.6 & 6.51 & 6.14 & 0.60 & 8.21 & 4.56 & 1.51 \\
\hline SEM & \pm 3.5 & \pm 3.4 & \pm 2.7 & \pm 1.85 & \pm 1.64 & \pm 1.46 & \pm 2.01 & \pm 2.77 & \pm 1.67 \\
\hline \multicolumn{10}{|l|}{ Day 10} \\
\hline Mean & 64.3 & 58.3 & 61.9 & 6.22 & 0.34 & -0.12 & 11.03 & 1.26 & 3.18 \\
\hline SEM & \pm 3.7 & \pm 3.8 & \pm 2.7 & \pm 1.84 & \pm 1.79 & \pm 1.48 & \pm 2.90 & \pm 2.72 & \pm 1.74 \\
\hline
\end{tabular}

SEM, standard error of the mean; MVA, motor vehicle accident; SAFE, safe driving; NEW, never-before-seen 
The recognition accuracy for MVA and SAFE stimuli decreased simultaneously (Fig. 1A). We observed a significant main effect of day $\left(F_{(1,668)}=8.76, P=0.032\right.$; Fig. 1A) on accuracy but not of context $(P=0.622)$ or day-context interaction $(P=$ $0.250)$.

On day 10, the fear ratings for SAFE stimuli decreased independent of those for MVA stimuli, regardless of the correctness of event recognition (Fig. 2B). We found a significant main effect of context on the change in fear ratings $\left(F_{(1,664)}=8.27\right.$, $P=0.0042)$ and a significant context-day interaction $\left(F_{(1,664)}=\right.$ 3.94, $P=0.0476$; Fig. $1 \mathrm{~B})$ but no significant main effect of day $(P=0.231)$, correctness $(P=0.276)$, or other interactions (day-correctness, $P=0.490 ; \quad$ context-correctness, $P=0.352$; context-day-correctness, $P=0.783$ ). The change in fear ratings significantly differed between MVA and SAFE stimuli on day 10 $\left(t_{(167)}=3.46, P=0.0007\right)$ but not day $1(P=0.510$; follow-up $t$-tests). The fear ratings for MVA stimuli on days 1 and 10 did not significantly differ $(P=0.441)$, but those for SAFE stimuli $\operatorname{did}\left(t_{(167)}=4.00, P<0.0001\right)$.

Psychophysiological reactions to both correctly and incorrectly recognized stimuli did not significantly differ. SCRs to the MVA and SAFE stimuli in both recognition sessions did not significantly differ from the baseline SCRs $(2$ [context] $\times 3$ [session] ANOVA; $P \geq 0.05$ ). No significant main effect or interaction(s) was observed in the case of the change in SCRs to MVA and SAFE stimuli.

Emotion recognition does not directly contribute to immediate or delayed event recognition. Recognition accuracy and change in fear ratings were not significantly correlated on both experimental days (Pearson's correlation coefficients; day 1: $r=$ $0.189, P=0.112$; day $10: r=-0.007, P=0.953)$. Emotion recognition also does not contribute to immediate or delayed psychophysiological reaction. Change in fear ratings and change in

A
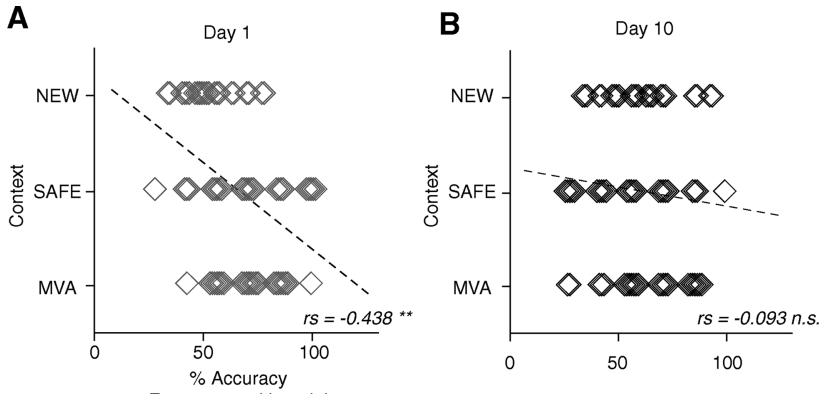

C Event-recognition trial

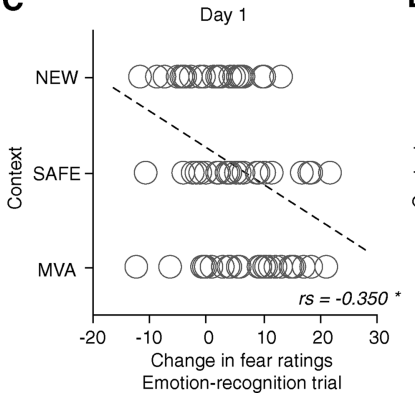

D

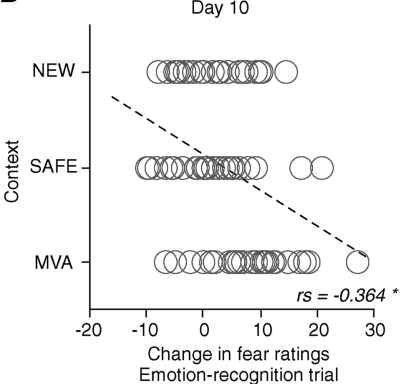

Figure 2. Relation between context and recognition performance with regression lines. $(A-C)$ The vertical axis represents the contextual category of the stimuli, and the horizontal axis represents the mean recognition performance (accuracy or change in fear ratings). (A) The contextual category was significantly correlated with the recognition accuracy on day 1 and $(C, D)$ with the change in fear ratings on days 1 and 10 , respectively. (B) However, it was not correlated with the recognition accuracy on day 10. ${ }^{*} P<0.005, * * P<0.001$.
SCRs were not significantly correlated on both experimental days (day 1: $r=-0.002, P=0.974$; day 10: $r=-0.051, P=$ 0.350 ). To estimate the influence of prior experience of a contextual category on the accuracy of episodic memory recognition, Spearman's correlation coefficients between contextual category and recognition accuracy and between contextual category and change in fear ratings were calculated on both experimental days. For immediate memory, both event and emotion recognition accuracy independently predicted context experienced, but for delayed memory, only emotion recognition accurately predicted context. Accuracy and contextual category were significantly correlated on day $1\left(r_{s}=-0.438, N=72, P=0.0002\right.$; Fig. $2 \mathrm{~A})$ but not on day $10\left(r_{s}=-0.093, N=72, P=0.432\right.$; Fig. 2B). However, the change in fear ratings was significantly correlated to contextual category on both days 1 and $10\left(r_{s}=-0.350, N=\right.$ 72, $P=0.0032 ; r_{s}=-0.364, N=72, P=0.0021 ;$ Fig. $2 \mathrm{C}, \mathrm{D}$, respectively).

Although the behavioral features in our study probably share a common neural background corresponding to the contextual category, the event- and emotion-oriented performance in memory-recognition tasks differed. Our results suggest that in healthy humans, the temporal change in fear rating but not in recognition accuracy differs between MVA and SAFE episodes. The change in fear ratings for MVA stimuli on days 1 and 10 was identical, however, the recognition accuracy decreased with time. This finding indicates that the neural background corresponding to the event- and emotion-recognition paradigms is distinct, and the consolidation processes for event and emotion memory may be separate. Sense danger can be apprehended without remembering details of past aversive accidental events, i.e., emotional memory persists longer than event memory. It also suggests that emotional memory contributes to the recognition of past aversive episodes, and this contribution is separate from event memory. Emotion recognition does not aid event recognition because of the fragility of explicit event-emotion memory association. This notion is supported by the lack of correlation between the change in fear ratings and recognition accuracy on days 1 and 10. Episodic memory may comprise declarative and nondeclarative memory; the former corresponding to event memory, and the latter, to emotional memory (Squire and Alvarez 1995; Medford et al. 2005). The behavioral discrepancy between emotion and event recognition in our study may support this memory architecture and the existence of a separate neural network for processing emotional memory. Emotional judgments, which predominantly depend on amygdala-driven activity, might be more accurate than judgments depending on hippocampus-driven activity.

The recognition accuracy in both MVA and SAFE contexts decreased with time; on day 10, it nearly equaled the accuracy for the NEW stimuli. However, studies have reported that emotional memory selectively persists over extended periods (Bradley et al. 1992; Wagner et al. 2006). The discrepancy between our results and previous findings might be attributable to differences in study design. Previously used recognition cues encompassed overt emotional cues, whereas those in our study encompassed potentially emotional ones. Overt emotional cues presented with cues of event-related items may enhance OLD responses (viz. hit rates), regardless of the accuracy of episode recognition (Talarico and Rubin 2003; Sharot et al. 2004). However, potential emotional cues, even when presented with cues of event-related items, do not accelerate episodic recognition. The possible generalization of the fear-evoking effect of MVA stimuli to SAFE stimuli may have decreased the difference between the recognition accuracy for these stimuli. The changes in fear ratings indicate that the fear-evoking effect of MVA stimuli may have generalized to SAFE stimuli on day 1; these effects were 
mitigated on day 10. Natural memory extinction may have operated in stimulus recognition because of the exposure to cars in daily life.

Further, this generalization might occur at the level of the higher cognitive centers via a mechanism distinct from contextual fear conditioning (Rudy and Pugh 1986). Incorrectly recognized MVA stimuli seemed to be perceived as more fear-evoking than correctly recognized stimuli, although the difference was not significant. Moreover, dissociate consolidation of event and emotion recognition may occur since the recognition accuracy decreased and the change in fear ratings increased with time for incorrectly recognized MVA stimuli. This conceivably suggests that the more fearsome the event, the more likely it is to be inaccurately recognized. This notion is highly discrepant to previous experimental findings, but does not contradict the clinical findings of peritraumatic amnesia (van der Kolk and Fisler 1995), which influences posttraumatic stress disorder (PTSD) development after MVA (Vaiva et al. 2003). Further research is required to clarify this notion.

MVA commonly causes PTSD and is the most frequent traumatic event experienced by men and the second most-frequent traumatic event experienced by women (Hamanaka et al. 2006; Kupchik et al. 2007). The encoding stimuli in this study may simulate PTSD triggers. Both event-emotion association and generalization of fear to an analogous episodic memory are preserved in PTSD patients (Rubin et al. 2008), suggesting that traumatic memory remains in the immature mnemonic state-a condition analogous to the persistence of an immediate negative episodic memory. Thus, the generalization of the fear experienced during a past traumatic event to another similar event may be powerfully retained in both immediate and delayed memory as a consequence of overadaptation.

\section{Acknowledgments}

This work was supported by a grant from Core Research for Evolutional Science and Technology (CREST), Japan Science and Technology (JST) Corporation. We thank the Japan Traffic Accident Identification Research Institute for providing hard-tofind movies of car crashes.

\section{References}

Adolphs R, Cahill L, Schul R, Babinsky R. 1997. Impaired declarative memory for emotional material following bilateral amygdala damage in humans. Learn Mem 4: 291-300.

Bradley MM, Greenwald MK, Petry MC, Lang PJ. 1992. Remembering pictures: Pleasure and arousal in memory. J Exp Psychol Learn Mem Cogn 18: $379-390$.

Breslau N. 2001. Outcomes of posttraumatic stress disorder. J Clin Psychiatry (Suppl. 17) 62: 55-59.

Cahill L, Babinsky R, Markowitsch HJ, McGaugh JL. 1995. The amygdala and emotional memory. Nature 377: 295-296.

Coles ME, Heimberg RG. 2002. Memory biases in the anxiety disorders: Current status. Clin Psychol Rev 22: 587-627.

Dimberg U. 1987. Facial reactions, autonomic activity and experienced emotion: A three component model of emotional conditioning. Biol Psychol 24: 105-122.
Gupta R, Duff MC, Denburg NL, Cohen NJ, Bechara A, Tranel D. 2009. Declarative memory is critical for sustained advantageous complex decision-making. Neuropsychologia 47: 1686-1693.

Hamanaka S, Asukai N, Kamijo Y, Hatta K, Kishimoto J, Miyaoka H. 2006. Acute stress disorder and posttraumatic stress disorder symptoms among patients severely injured in motor vehicle accidents in Japan. Gen Hosp Psychiatry 28: 234-241.

Kupchik M, Strous RD, Erez R, Gonen N, Weizman A, Spivak B. 2007. Demographic and clinical characteristics of motor vehicle accident victims in the community general health outpatient clinic: A comparison of PTSD and non-PTSD subjects. Depress Anxiety 24: 244-250.

LaBar KS, Cabeza R. 2006. Cognitive neuroscience of emotional memory. Nat Rev Neurosci 7: 54-64.

LaBar KS, LeDoux JE. 1996. Partial disruption of fear conditioning in rats with unilateral amygdala damage: Correspondence with unilateral temporal lobectomy in humans. Behav Neurosci 110: 991-997.

Macmillan NA, Creelman CD. 1991. Detection theory: A user's guide. Cambridge University Press, New York.

Maratos EJ, Dolan RJ, Morris JS, Henson RN, Rugg MD. 2001. Neural activity associated with episodic memory for emotional context. Neuropsychologia 39: 910-920.

Medford N, Phillips ML, Brierley B, Brammer M, Bullmore ET, David AS. 2005. Emotional memory: Separating content and context. Psyc Res Neuroimaging 138: 247-258.

Rubin DC, Berntsen D, Bohni MK. 2008. A memory-based model of posttraumatic stress disorder: Evaluating basic assumptions underlying the PTSD diagnosis. Psychol Rev 115: 985-1011.

Rudy JW, Pugh CR. 1986. A comparison of contextual and generalized auditory-cue fear conditioning: Evidence for similar memory processes. Behav Neurosci 110: 1299-1308.

Schell AM, Dawson ME, Marinkovic K. 1991. Effects of potentially phobic conditioned stimuli on retention, reconditioning, and extinction of the conditioned skin conductance response. Psychophysiology 28: $140-153$.

Sharot T, Delgado MR, Phelps EA. 2004. How emotion enhances the feeling of remembering. Nat Neurosci 7: 1376-1380.

Smith APR, Henson RN, Dolan RJ, Rugg MD. 2004. fMRI correlates of the episodic retrieval of emotional contexts. Neuroimage 22: 868-878.

Smith APR, Henson RN, Rugg MD, Dolan RJ. 2005. Modulation of retrieval processing reflects accuracy of emotional source memory. Learn Mem 12: $472-479$.

Squire LR. 1992. Memory and the hippocampus: A synthesis from findings with rats, monkeys, and humans. Psychol Rev 99: 195-231.

Squire LR, Alvarez P. 1995. Retrograde amnesia and memory consolidation: A neurobiological perspective. Curr Opin Neurobiol 5: $169-177$.

Suzuki WA. 2009. Perception and the medial temporal lobe: Evaluating the current evidence. Neuron 61: 657-666.

Talarico JM, Rubin DC. 2003. Confidence, not consistency, characterizes flashbulb memories. Psychol Sci 14: 455-461.

Turnbull OH, Evans CE. 2006. Preserved complex emotion-based learning in amnesia. Neuropsychologia 44: 300-306.

Vaiva G, Brunet A, Lebigot F, Boss V, Ducrocq F, Devos P, Laffargue P, Goudemand M. 2003. Fright (effroi) and other peritraumatic responses after a serious motor vehicle accident: Prospective influence on acute PTSD development. Can J Psychiatry 48: 395-401.

van der Kolk BA, Fisler R. 1995. Dissociation and the fragmentary nature of traumatic memories: Overview and exploratory study. J Trauma Stress 8: $505-525$.

Wagner U, Hallschmid M, Rasch B, Born J. 2006. Brief sleep after learning keeps emotional memories alive for years. Biol Psychiatry 60: $788-790$.

Zola-Morgan S, Squire LR. 1990. The primate hippocampal formation: Evidence for a time-limited role in memory storage. Science 250: $288-290$.

Received November 6, 2009; accepted in revised form January 15, 2010. 


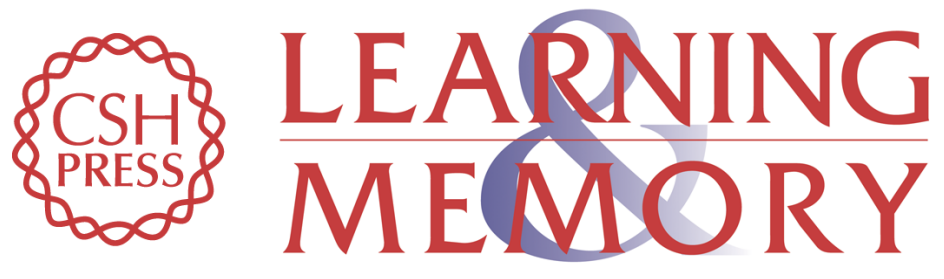

\section{Emotional memory persists longer than event memory}

Kenichi Kuriyama, Takahiro Soshi, Takeshi Fujii, et al.

Learn. Mem. 2010, 17:

Access the most recent version at doi:10.1101//m.1651910

Supplemental http://learnmem.cshlp.org/content/suppl/2010/03/01/17.3.130.DC1

Material

References This article cites 28 articles, 3 of which can be accessed free at: http://learnmem.cshlp.org/content/17/3/130.full.html\#ref-list-1

License

Email Alerting Receive free email alerts when new articles cite this article - sign up in the box at the Service top right corner of the article or click here. 